\title{
Capsule Commentary on Kovacs et al. Systematic Review and Meta-analysis of the Effectiveness of Implementation Strategies for Non-communicable Disease Guidelines in Primary Health Care
}

\author{
Joseph Truglio, MD MPH \\ J Gen Intern Med 33(7):1141 \\ DOI: $10.1007 / \mathrm{s} 11606-018-4473-\mathrm{Z}$ \\ (c) Society of General Internal Medicine 2018
}

Icahn School of Medicine at Mount Sinai, New York City, USA.

$\mathrm{T}$ he question of "what is the best technique to improve guideline implementation" is broad, due to the wide variety of clinical settings, patient populations, and guidelines to be considered. It is also a question of increasing importance as systems move towards value-based care contracts, with "value" often defined by the insurer and linked to guidelinebased care delivery. Kovacs et al. ${ }^{1}$ attempt to answer this question with a systematic review of guideline implementation strategies in primary care. After analyzing 192 outcomes in 36 studies evaluating six intervention schemes, the authors found single-component interventions to be equally effective as complex multifaceted interventions in improving both process of care and, most notably, outcomes. Their findings speak to the need to simplify interventions and tailor them to the individual providers and communities where care is delivered. The authors comment on the sparsity of organizational-level interventions, with most interventions focused on changing individual clinician behavior-a finding previously reported. ${ }^{2,3}$ Given the challenges in consistently changing behavior, and the difficulty in scaling a single intervention to impact multiple clinicians, there is clearly a need for studies evaluating structural change and system-level interventions. If the goal is for recommended services to reach patients, it may not be necessary to change clinician behavior, but rather to change the system in which care is delivered. Economic analyses and assessments of balance measures are also noticeably absent from the studies analyzed. It is difficult for systems to develop strategies to improve adherence to guidelines without

understanding the cost-both financial cost and the cost of unintended consequences. In recent years, there has been a significant growth of population health and a shift towards the triple aim of improving the health of a population, improving the quality of the care delivered, and decreasing the cost of that care. ${ }^{4}$ This growth creates an opportunity to examine the ability of population health management interventions to improve adherence to guidelines at the systems level, with particular attention paid to the ultimate quality of the care delivered and the cost of such interventions.

Corresponding Author: Joseph Truglio, MD MPH; Icahn School of Medicine at Mount Sinai, New York City, USA (e-mail: Joseph. Truglio@mssm.edu).

\section{Compliance with Ethical Standards:}

Conflict of Interest: The author declares that he does not have a conflict of interest.

\section{REFERENCES}

1. Kovacs E, Strobl R, Phillips A, Stephan AJ, Müller M, Gensichen J, DiplPad Grill E, Hoffman A. Systematic review and meta-analysis of the effectiveness of implementation strategies for non-communicable disease guidelines in primary health care. $\mathrm{J}$ Gen Intern Med.

2. Grimshaw JM, Thomas RE, MacLennan G, Fraser C, Ramsay CR, Vale L, et al. Effectiveness and efficiency of guideline dissemination and implementation strategies. Health technology assessment (Winchester, England). 2004;8(6): 1-72.

3. Prior M, Guerin M, Grimmer-Somers K. The effectiveness of clinical guideline implementation strategies - a synthesis of systematic review findings. Journal of Evaluation in Clinical Practice. 2008;14(5):888-97. https://doi.org/10.1111/j.1365-2753.2008.01014.x

4. McCarthy, D, Klein, S. The triple aim journey: improving population health and patients' experience of care, while reducing costs. Commonwealth Fund Web site. http://mobile.commonwealthfund.org/ /media/Files/ Publications/Case\%20Study/2010/Jul/Triple\%20Aim\%20v2/1421_McCarthy_triple_aim_journey_overview.pdf. Accessed 10 April 2018.

Published online May 7, 2018 